\title{
Plasmids derived from Gifsy-1/Gifsy-2, lambdoid prophages contributing to the virulence of Salmonella enterica serovar Typhimurium: implications for the evolution of replication initiation proteins of lambdoid phages and enterobacteria \\ Correspondence \\ Borys Wróbel \\ bwrobel@iopan.gda.pl \\ Received 11 September 2006 \\ Revised 7 February 2007 \\ Accepted 14 February 2007

\author{
Bartosz Słomiński, ${ }^{1}$ Joanna Całkiewicz, ${ }^{2}$ Piotr Golec, ${ }^{1}$ \\ Grzegorz Węgrzyn ${ }^{1,2}$ and Borys Wróbel ${ }^{2}$ \\ ${ }^{1}$ Department of Molecular Biology, University of Gdańsk, Kładki 24, 80-822 Gdańsk, Poland
${ }^{2}$ Department of Genetics and Marine Biotechnology, Institute of Oceanology, Polish Academy of
Sciences, Powstańców Warszawy 55, 81-712 Sopot, Poland
} \\ Gifsy-1 and Gifsy-2 are lambdoid prophages which contribute to the virulence of Salmonella enterica serovar Typhimurium. The nucleotide sequence of the replication region of both prophages is identical, and similar in organization to the replication region of bacteriophage $\lambda$. To investigate the replication of the Gifsy phages and the relationship between Gifsy and host chromosome replication, a plasmid which contained all the genes and regulatory sequences required for autonomous replication in bacterial cells was constructed. This plasmid, pGifsy, was stably maintained in Escherichia coli cells. The helicase loader of the Gifsy phages is very similar to the DnaC protein of the host, a feature characteristic of a large group of prophages common in the sequenced genomes of pathogenic enterobacteria. This DnaC-like protein showed no similarity to the helicase loader of bacteriophage $\lambda$ and closely related phages. Interestingly, unlike plasmids derived from bacteriophage $\lambda$ ( $\lambda$ plasmids), pGifsy did not require a gene encoding the putative helicase loader for replication, although deletion of this gene resulted in a decrease in plasmid copy number. Under these conditions, it was shown that the plasmid utilized the helicase loader coded by the host. On the other hand, the viral protein could not substitute for DnaC in bacterial chromosome replication. The results of the current study support the hypothesis that the enterobacterial helicase loader is of viral origin. This hypothesis explains why the gene for DnaC, the protein central to both replication initiation and replication restart in $E$. coli, is present in the genomes of Escherichia, Shigella, Salmonella and Buchnera, but not in the genomes of related enterobacteria.
}

\section{INTRODUCTION}

Lambdoid bacteriophages have been basic models in molecular biology studies for many years (Friedman \& Court, 2001; Węgrzyn \& Węgrzyn, 2005). Recent observations that many toxins produced by pathogenic bacteria are encoded by prophages related to $\lambda$ (for recent reviews, see Brussow et al., 2004; Herold et al., 2004) have rekindled the interest in this group of viruses.

The properties of the replication-regulation region of lambdoid prophages can be conveniently investigated using plasmids derived from these viruses. Indeed, plasmids derived from bacteriophage $\lambda$ have been found to be very useful models in studies of replication in general (for a review, see Węgrzyn \& Węgrzyn, 2002). These plasmids are constructed by ligation of an antibiotic-resistance gene with a fragment of phage DNA containing all genes and regulatory sequences required for autonomous replication in bacterial cells. The replication-regulation region of bacteriophage $\lambda$ consists of the $p_{\mathrm{R}}$ promoter and cro, cII, $O$ and $P$ genes. The function of cro and $c I I$ is regulatory: cro is a repressor of the $p_{\mathrm{R}}$ promoter (Murotsu \& Matsubara, 1980; Ptashne, 1992), while $c I I$ is involved in the regulation of the lysogenic development of $\lambda$, and has no importance for the replication and maintenance of $\lambda$ plasmids.

Replication of $\lambda$ plasmid DNA is initiated at the ori $\lambda$ region, located in the middle of the $O$ gene (Fig. 1). This gene encodes the replication initiator protein, which binds to the replication origin, forming the nucleoprotein structure called the 'O-some'. The host-encoded DnaB helicase is delivered to the $\mathrm{O}$-some by another $\lambda$ replication protein, the $P$ gene product. The or $i \lambda / \mathrm{O} / \mathrm{P} / \mathrm{DnaB}$ structure, 
$\lambda$

ATCCCTCAAAACGAGGGA ATCCCCTAAAACGAGGGA AAAACATCCCTCAAATTGGGGGATTGC ATCCCTCAAAACAGGGG

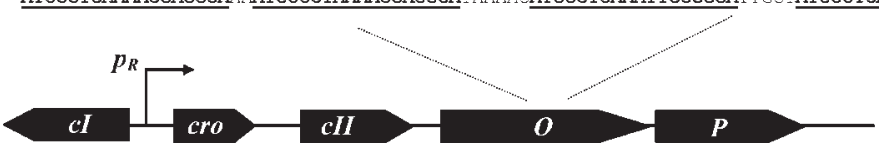

Gifsy

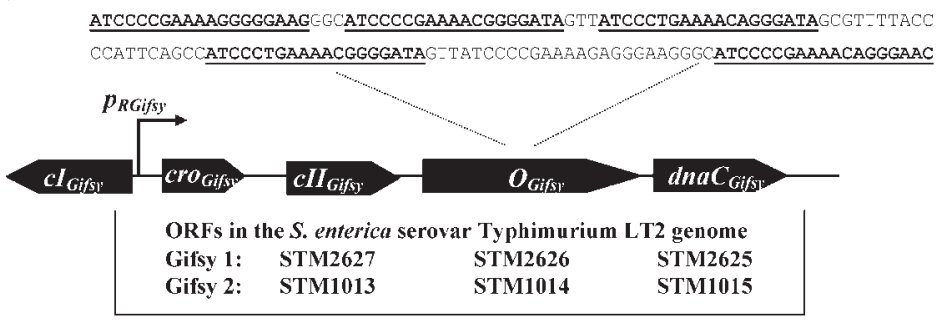

Region present in pGifsy

Fig. 1. Comparison of the regulation-replication regions of bacteriophage $\lambda$ and the Gifsy phages of S. enterica. ORF designations in the S. enterica serovar Typhimurium LT2 genome are shown for both Gifsy prophages. The insets show the putative iterons at the Gifsy origin compared with those of $\lambda$. called the 'pre-primosome', is stable but inactive in promoting DNA replication, as strong interactions between $\mathrm{P}$ and DnaB proteins prevent helicase activity of the latter component (unlike an analogous DnaC/DnaB complex that operates during initiation of Escherichia coli chromosome replication at oriC, which is quite unstable). Action of the heat-shock proteins DnaK, DnaJ and GrpE is necessary to liberate DnaB from P-mediated inhibition (for a review, see Taylor \& Węrzyn, 1995), although the P protein seems to still be present in the complex, and DnaK also remains bound to it (Potrykus et al., 2002).

The process of chaperone-dependent pre-primosome remodelling is coupled with transcriptional activation of orid (transcription proceeding in the replication origin region; for a review see Taylor \& Węgrzyn, 1995). Transcriptional activation of the origin is necessary for efficient initiation of $\lambda$ DNA replication in vivo, even if all the replication proteins are provided. It seems that changes in DNA topology caused by movement of RNA polymerase during transcription may play a crucial role in stimulation of replication initiation. The $\lambda p_{\mathrm{R}}$ promoter is a natural start site of transcription that produces mRNA for synthesis of $\lambda$ replication proteins ( $\mathrm{O}$ and $\mathrm{P}$ ), and acts to activate ori $\lambda$. The final step in the initiation of $\lambda$ DNA replication is binding of DNA polymerase III holoenzyme and accessory replication proteins (DNA gyrase, singlestranded DNA-binding protein, and other proteins), encoded by the host, to the orid region (for a review see Węgrzyn \& Węgrzyn, 2002).

Lambdoid phages Gifsy-1 and Gifsy-2 both contribute to the virulence of Salmonella enterica serovar Typhimurium, in which they were discovered (Figueroa-Bossi \& Bossi, 1999). Various virulence factors are associated with Gifsy phages (Figueroa-Bossi et al., 2001; Lawley et al., 2006), e.g. gipA (Gifsy-1; Stanley et al., 2000), gogB (Gifsy-1; Coombes et al., 2005), gtgE (Gifsy-2; Ho et al., 2002), gtgB/sseI (Gifsy-2; Miao \& Miller, 2000; Worley et al., 2000) and sodCI (Gifsy-2; De Groote et al., 1997; Farrant et al., 1997;
Fang et al., 1999; Sansone et al., 2002; Krishnakumar et al., 2004).

Gifsy prophages contain regions with an organization similar to that of the bacteriophage $\lambda$ replication region. In this work, we constructed a series of plasmids containing the replication region of Gifsy prophages, analogous to $\lambda$ plasmids, capable of autonomous replication in E. coli cells, in order to study the relationship between Gifsy and host chromosome replication.

\section{METHODS}

Bacterial strains and plasmids. pGifsy was constructed by PCR amplification using the host (S. enterica serovar Typhimurium LT2) genomic DNA as a template, and primers Gifsy-up 5'-CGG CCG AAT TCT AGA TAT CTC GAG AAC TTG CTG GAT ACG C-3' and Gifsy-dn 5'-CTG GAT CCG CTA GCG AGG AGC GCT TAT TTG ACA ATC CGG AGG TG-3'. The following thermal profile was used: $94{ }^{\circ} \mathrm{C}$ for $5 \mathrm{~min}$, then $30 \mathrm{cycles}$ of $94{ }^{\circ} \mathrm{C}$ for $30 \mathrm{~s}, 64{ }^{\circ} \mathrm{C}$ for $30 \mathrm{~s}, 72{ }^{\circ} \mathrm{C}$ for $1 \mathrm{~min}$ and final extension at $72{ }^{\circ} \mathrm{C}$ for $5 \mathrm{~min}$. Prophages Gifsy- 1 and Gifsy- 2 are identical at the nucleotide level in the amplified region, which corresponds to nt 2767 129-2 769658 (Gifsy-1 prophage) and $1105429-1107958$ (Gifsy-2 prophage) in the $S$. enterica serovar Typhimurium LT2 genome (GenBank accession no. NC_003197; McClelland et al., 2001). The PCR fragment, after digestion with $\mathrm{Xba \textrm {I }}$ and $\mathrm{BamHI}$, was ligated to a fragment carrying the tetracycline-resistance gene obtained by digesting pACYC184 with $X b a \mathrm{I}$ and $B c l I$. pGifsyNoLoader was derived from pGifsy by digestion with restriction endonucleases $X m n \mathrm{I}$ and BalI, and subsequent religation of blunt ends. Plasmids overexpressing the E. coli DnaC (pQE-EcoliDnaC) and DnaC homologues of E. coli $\mathrm{K}-12$ prophage Rac (pQE-RacDnaC) and S. enterica prophages Gifsy-1/Gifsy-2 (pQEGifsyDnaC) were constructed by cloning the appropriate PCR fragments into pQE60 (Qiagen) restricted with BamHI and NheI. This digestion placed the insert under a derivative of the $p_{\text {lac }}$ promoter and a strong translational signal. The native translation stop codon was used instead of the one present on the plasmid; therefore, the subsequently overproduced proteins did not contain the C-terminal His $\times 6$ tag. They did, however, contain additional amino acids at the $\mathrm{N}$ terminus coded by the vector (MGGSHY). The genomic DNA of the respective bacterial strains was used as a template in the PCR reactions. The specific thermal profiles are given in parentheses for 
each primer pair: Ecoli-dnaC-up 5'-GCC GAA GGA TCC CAT TAC ATG AAA AAC GTT GGC GAC C-3', Ecoli-dnaC-dn 5' -GCG CCG CTA GCC TAG GAT GTT AAT ACT CTT TAC CTG TTA CCC-3' $\left(94{ }^{\circ} \mathrm{C}\right.$ for $5 \mathrm{~min}, 30$ cycles at $94{ }^{\circ} \mathrm{C}$ for $30 \mathrm{~s}, 62{ }^{\circ} \mathrm{C}$ for $30 \mathrm{~s}, 72{ }^{\circ} \mathrm{C}$ for $1 \mathrm{~min}$, and final extension at $72^{\circ} \mathrm{C}$ for $5 \mathrm{~min}$ ); RacP-up $5^{\prime}$-GGG GCG CGG GGT GGA ATT CAA GGA TCC CAT TAC ATG AAA AAT ATT GCG ACA GGC-3', RacP-dn 5'-GCC AAG CTA GCT TGG ATT CTC ACC AAT AAA AAA CGC CCG GTC AAG ATC TTA CTT CGC AAT TCC TGG CTG-3' $\left(94{ }^{\circ} \mathrm{C}\right.$ for $5 \mathrm{~min}$, five cycles of $94{ }^{\circ} \mathrm{C}$ for $30 \mathrm{~s}, 48{ }^{\circ} \mathrm{C}$ for $30 \mathrm{~s}, 72{ }^{\circ} \mathrm{C}$ for $1 \mathrm{~min}, 25$ cycles of $94{ }^{\circ} \mathrm{C}$ for $30 \mathrm{~s}, 55^{\circ} \mathrm{C}$ for $30 \mathrm{~s}$, $72{ }^{\circ} \mathrm{C}$ for $1 \mathrm{~min} 30 \mathrm{~s}$, and final extension at $72{ }^{\circ} \mathrm{C}$ for $5 \mathrm{~min}$ ); GifsyDnaC-up 5'-GGA ATT CAA GGA TCC CAT TAC ATG AAA AAC GTA ATC GG-3', GifsyDnaC-dn 5'-CTC GAG CTA GCC TAG GAT GTC AAG AAT AAT CAT CCG TT- $3^{\prime}\left(94{ }^{\circ} \mathrm{C}\right.$ for $5 \mathrm{~min}$, five cycles at $94{ }^{\circ} \mathrm{C}$ for $30 \mathrm{~s}, 48{ }^{\circ} \mathrm{C}$ for $30 \mathrm{~s}, 72{ }^{\circ} \mathrm{C}$ for $1 \mathrm{~min}, 25$ cycles at $94{ }^{\circ} \mathrm{C}$ for $30 \mathrm{~s}, 59^{\circ} \mathrm{C}$ for $30 \mathrm{~s}, 72{ }^{\circ} \mathrm{C}$ for $1 \mathrm{~min} 30 \mathrm{~s}$, and final extension at $72{ }^{\circ} \mathrm{C}$ for $5 \mathrm{~min}$ ). The structure of all plasmids was confirmed by restriction analysis and sequencing.

The plasmids carrying the bacterial dnaC (pINC) and dnaB (pINB) genes under the control of the $p_{\text {ara }}$ promoter have been described by Allen \& Kornberg (1991). DnaC or DnaB overproduction in bacteria carrying these plasmids was induced by addition of $0.1 \%$ arabinose.

pCB104 (Boyd \& Sherratt, 1995) is a standard $\lambda$ plasmid bearing chloramphenicol resistance. pKB $2 \pi$ is a $\lambda$ plasmid bearing a G410T (Arg137Gly) mutation in the $P$ gene (Kur et al., 1987; Wegrzyn et al., 1996).

Derivatives of E. coli K-12 strains were used in all the experiments. MG1655 (wild-type strain; Jensen, 1993) was used to determine plasmid copy number and in the experiments on plasmid comaintenance. XL1-Blue $\left(\mathrm{F}^{\prime}:: \operatorname{Tn} 10\right.$ proA $^{+} B^{+}$lacl ${ }^{\mathrm{q}} \Delta($ lacZ $)$ M15/ recA1 endA1 gyrA96 $\left(\mathrm{Nal}^{\mathrm{r}}\right)$ thi hsdR17 $\mathrm{r}_{\mathrm{K}}^{-} \mathrm{m}_{\mathrm{K}}^{+}$supE44 relA1 lac; Bullock et al., 1987) was used in overexpression experiments to allow for better control of the plac promoter. The effects of the dna 1 (ts) mutation on the replication of Gifsy plasmids were measured in DG765519 (leuB6 thyA47 deoC3 rpsL) and its otherwise isogenic dnaC1(ts) derivative PC15030 (Kędzierska et al., 2003). The effects of the dnaA46(ts) mutation on plasmid replication have been investigated using WAM106 (Thomas \& Glass, 1991) and its otherwise isogenic dnaA46(ts) derivative (Słomińska et al., 2003). The dependence of pGifsy on molecular chaperones has been tested using W3101 ( $g a l E$ sup $^{+}$; Lipińska et al., 1989), and its otherwise isogenic derivatives bearing dnaK756 (Georgopoulos \& Herskovitz, 1971; Georgopoulos, 1977; strain W3101K) or dnaJ (Yochem et al., 1978; strain W3101J) mutations. In the experiments on plasmid replication in amino acid-starved cells, the strains CP78 [leu arg thr his thi $\left(\lambda^{\mathrm{W}}\right)$; Fiil \& Friesen, 1968; Wróbel et al., 1998b] and CP79 (same as CP78, but relA2; Fiil \& Friesen, 1968; Wróbel et al., 1998b) were used.

Estimation of the efficiency of transformation, plasmid copy number and relative plasmid amount after temperature upshift and in amino acid-starved bacteria. The procedures described by Węgrzyn et al. (1996) were employed. Bacterial growth was monitored by measurement of culture $\mathrm{OD}_{575}$. The plasmid amount relative to bacterial cell mass (determined by OD measurement) was measured densitometrically after isolation from samples taken at indicated time intervals, after temperature upshift in the E. coli dnaC1(ts) and dnaA46(ts) strains, or after the onset of isoleucine starvation in the E. coli relA and relA ${ }^{+}$strains. We report the mean results from three independent experiments. Isoleucine starvation of bacteria growing in a minimal medium was induced by addition of $\mathrm{L}-$ valine to a final concentration of $1 \mathrm{mg} \mathrm{ml}^{-1}$, as described previously (Węgrzyn et al., 1991).
Plasmid compatibility. Plasmids bearing different antibiotic-resistance genes were introduced into E. coli cells (MG1655). After overnight growth in the presence of all the antibiotics, the bacteria were plated on plates lacking the antibiotic neutralized by one of the plasmids. Then, 100 colonies were tested for growth on plates containing the antibiotic lacking in the previous step.

\section{RESULTS}

\section{Analysis of the Gifsy regulation-replication module}

The replication-regulation region of bacteriophage $\lambda$ consists of the $p_{\mathrm{R}}$ promoter and four genes: cro, cII, O and $P$. Only $O$ and $P$ are necessary for replication, the two shorter genes code for DNA-binding regulatory proteins. The Gifsy-1 genome contains a region with a similar organization: a promoter, two short and two longer ORFs (Fig. 1). Although other symbols (ORF numbers) for these genes have been used during $S$. enterica serovar Typhimurium LT2 genome sequencing, in this work they are referred to as cro $_{\text {Gifsy }}, c I_{\text {Gifsy }}$ (ORF STM2627 in Gifsy-1 region, STM1013 in Gifsy-2), $O_{\text {Gifsy }}$ (STM2626 and STM1014, respectively) and $d n a C_{\text {Gifsy }}$ (STM2625 and STM1015; see below).

The homology between the two putative regulatory proteins of Gifsy prophages (79 and 124 aa, respectively) and their counterparts in $\lambda$ (67 and $94 \mathrm{aa}$ ) is not obvious. They do not show significant similarity at the nucleotide or amino acid level when the BLAST2 algorithm is used, and the expected values are calculated based on the size of the non-redundant GenBank database. However, when a more exact method to calculate protein similarity was used (Smith-Waterman algorithm implemented in PRSS3, part of the FASTA package; Pearson, 1996), and the expectancy values were calculated based on shuffling one of the sequences 1000 times, the similarity between the products of $c I I_{\text {Gifsy }}$ and $\lambda c I I$ was significant (using the BLOSUM65 matrix, the penalty was 12 for gap opening and 2 for gap extension). The putative $c r o_{\text {Gifsy }}$ and $c I I_{\text {Gifsy }}$ products both contain a helix-turn-helix motif (Dodd \& Egan, 1987, 1990; algorithm implemented in HELIXTURNHELIX, part of the EMBOss package; Rice et al., 2000), which suggests that they are DNA-binding proteins. Moreover, they show similarity with products of ORFs of other phages or prophages in the family, for example, the product of $c I_{\text {Gifsy }}$ with the putative regulator of lysogeny of the Salmonella phage L (Schicklmaier \& Schmieger, 1997). We conclude that the two shorter reading frames in Gifsy prophages code for regulatory proteins.

Replication of $\lambda$ plasmid DNA is initiated at the ori $\lambda$ region. This region is located in the middle of the $O$ gene, and contains four repeated iteron sequences. The $\mathrm{O}$ protein interacts with these $19 \mathrm{nt}$ repeats with its $\mathrm{N}$-terminal part; the C-terminal part interacts with the second replication protein $\mathrm{P}$, coded by a downstream gene. $\mathrm{P}$ in turn interacts with the host DNA helicase DnaB. Analysis of the $O_{\text {Gifsy }}$ 
gene shows that it contains five repeats followed by an ATrich region, and has a structure very similar to that of ori (Tsurimoto \& Matsubara, 1981a, b; Fig. 1). These repeats (ATCCCc/tGAAAACGGGGATA) are highly similar to $\lambda$ iterons (ATCCCTCAAAACGa/gGGGAt/a), which is expected considering the high similarity of the DNAbinding $\mathrm{N}$-terminal part of $\mathrm{O}_{\text {Gifsy }}$ to the corresponding protein region in $\lambda \mathrm{O}$ (Wróbel \& Węgrzyn, 2002). However, the C-terminal part of the protein resembles the amino acid sequence of the host protein DnaT. This concerns especially the C-terminal 18 aa of these proteins, which show $68.4 \%$ identity and $73.7 \%$ similarity. We have speculated previously that this C-terminal sequence motif might be involved in the interaction with the helicase loader (Wróbel \& Węgrzyn, 2002).

The second replication protein of Gifsy prophages (which we named DnaC $_{\text {Gifsy }}$ ) is similar to DnaC, the host helicase loader whose gene follows dnaT in the host genome ( $47.6 \%$ identity and $67.2 \%$ similarity in a global alignment obtained with the Needleman-Wunsch algorithm using default parameter values implemented in program NEEDLE, part of the EMBOss package; Rice et al., 2000). DnaC ${ }_{\text {Gifsy }}$ shows no significant similarity to the bacteriophage $\lambda$ protein P (Wróbel \& Węgrzyn, 2002). This suggests that while the first steps of building the Gifsy replication complex probably resemble the assembly of the $\lambda$ replication complex (binding of the $\mathrm{O}$ protein to the origin and $\mathrm{O}$-some formation), the subsequent steps may be different, since Gifsy phages apparently use a helicase loader closely related to that of the host.

\section{Phylogenetic analysis of bacteriophage DnaC homologues}

In order to investigate the evolutionary relationships between the Gifsy replication module and (i) the replication region of other phages encoding a homologous helicase loader, and (ii) the dnaT-dnaC region in the genomes of enterobacteria, we searched the GenBank nonredundant database and the database of wholly sequenced genomes at the National Center for Biotechnology Information site for homologues of enterobacterial DnaC. Apart from the members of the genera Escherichia, Shigella, Salmonella and Buchnera (enterobacterial intracellular symbionts of aphids), no other $\gamma$-proteobacterial genome carried non-viral DnaC-like proteins. The only group of bacteria in which helicase loaders have been identified are Gram-positive bacteria related to Bacillus (Wróbel \& Węgrzyn, 2002). In the preliminary phylogenetic analysis, the sequences of helicase loaders from $\gamma$ proteobacteria and their phages were clearly separated from the sequences of helicase loaders present in the genomes of Gram-positive bacteria and their phages (not shown), and only the $\gamma$ proteobacterial sequences were used in further analysis. The sequences were aligned using CLUSTALW (the alignment was corrected manually). JTT (Jones et al., 1992), a substitution model optimal under the Akaike Information Criterion (program ProtTest, Abascal et al., 2005), was used in all analyses. Programs PROTDIST and NEIGHBOR (parts of the PHYLIP package; Felsenstein, 2005) were used to construct the neighbour-joining tree presented in Fig. 2. The support for the interior branches was measured using the bootstrap method with SEQBOOT and CONSENSE (parts of PHYLIP), and the weighted least-squares likelihood ratio test using program WeightLESS (Sanjuán \& Wróbel, 2005).

The presence of the dnaT-dnaC operon was detected only in two enterobacterial lineages: one led to Escherichial Shigella and Salmonella, and the other to the enterobacterial symbionts of aphids (Buchnera) (Fig. 2). The separation between these two lineages has been estimated to have occurred 200 million years ago (Clark et al., 1999; Lerat et al., 2003). It is particularly interesting that there was a lack of $d n a C$ in bacteria proposed to be closely related to the free-living branch of enterobacteria (in particular, Yersinia) or the endosymbiont branch (in particular, Wigglesworthia and Blochmannia). However, if the hypothesis of the acquisition of the helicase loader from the lambdoid phages is true (Wróbel \& Węgrzyn, 2002), it was probably a one-off event. All genomes of free-living enterobacteria that contain a $d n a C$-like gene also contain $d n a T$, whose product is involved in the mechanisms for reloading the replication machinery after replication-fork breakdown (Sandler, 2000; Boonsombat et al., 2006; Heller \& Marians, 2005). This is also true for the Buchnera genomes, with the exception of Buchnera from Baizongia pistaciae (which suggests a recent loss rather than independent acquisition in the Buchnera lineage). Thus, the evidence indicates that the adaptation of the dnaT$d n a C$ system for host replication occurred once in enterobacteria. It is likely that it involved adaptive changes in other genes encoding the members of both the oriC initiation and replication-restart complexes.

The enterobacterial DnaC sequences form a monophyletic cluster with viral helicase loaders from a large group of prophages present in enterobacterial genomes, and are likely to be involved in the virulence of their hosts (Wróbel \& Węgrzyn, 2002). Within the cluster of lambdoid helicase loaders, DnaC-like proteins from Gifsy phages formed a group separate from those similar to the helicase loader of the Rac prophage present in the E. coli K-12 genome.

Helicase loaders of viruses infecting other groups of bacteria (Pseudomonas and Burkholderia) are quite distant from this group of DnaC-like sequences. The other more distantly related group of viruses related to phage P27 carry in their replication region three genes which probably code for an iteron-binding protein, a helicase loader and a helicase, in that order. The helicase encoded by these viruses is closely related to the helicases of the lambdoid phages that carry two genes only (for an iteron-binding protein and a helicase; data not shown).

Three amino acids suspected to be involved in the interaction with DnaB (Nakayama et al., 1987; Ludlam et al., 2001; Wróbel \& Węgrzyn, 2002) are conserved in the 


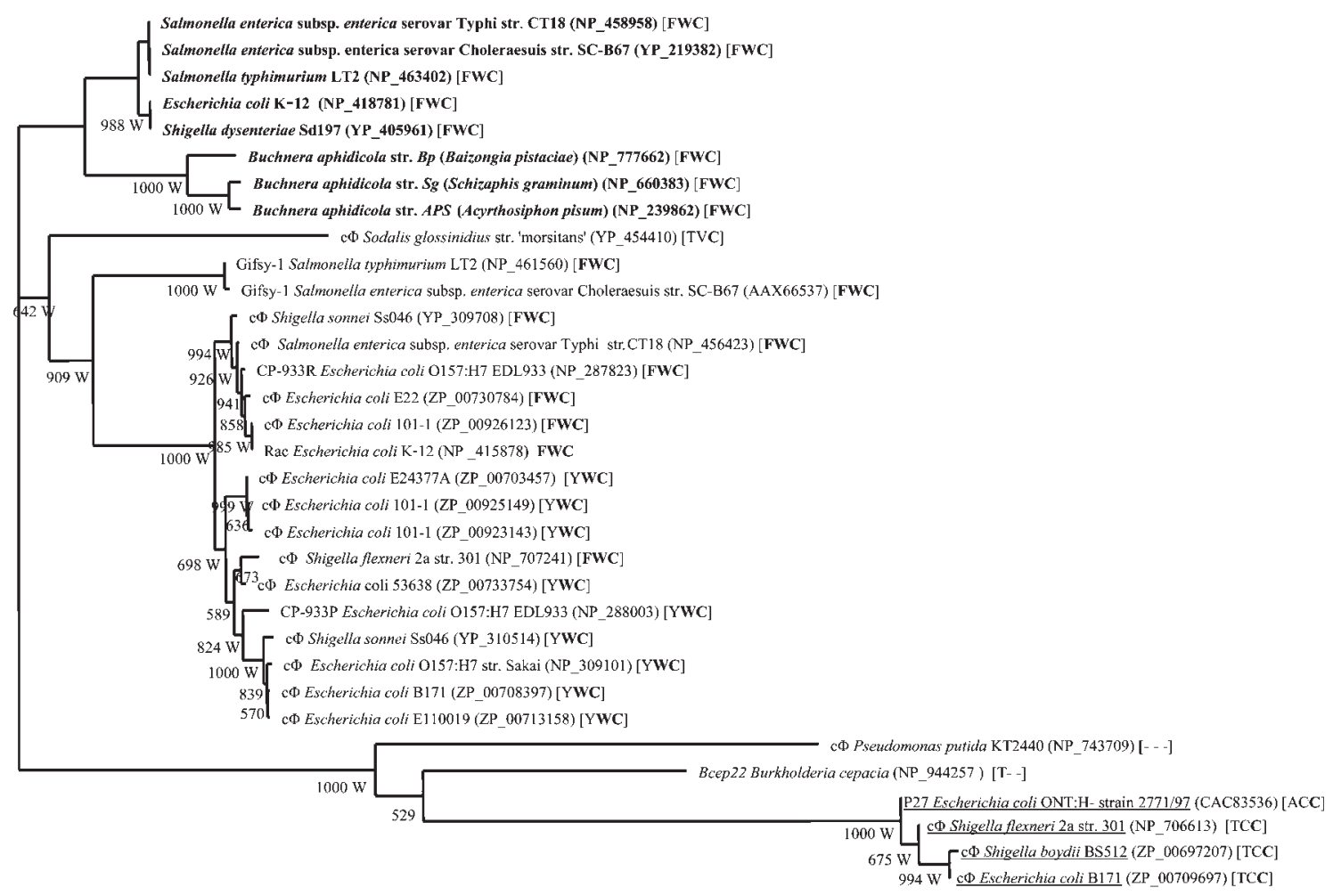

Fig. 2. Neighbour-joining tree of enterobacterial DnaC proteins and related phage helicase loaders. The proteins involved in the replication of the host chromosome are shown in bold type. The proteins of four lambdoid phages and prophages encoded by a gene followed by a gene for a viral helicase are underlined. Values above the interior branches are bootstrap frequencies; W, branch significantly longer than zero, according to the weighted least-squares likelihood ratio test (Sanjuán and Wróbel, 2005). Three conserved residues in DnaC-like proteins, perhaps involved in the interaction with DnaB and corresponding to Phe23, Trp32 and Cys69 in the E. coli protein, are shown in brackets; -, no apparent conservation at the amino acid positions; GenBank accession numbers are given in parentheses.

DnaC-like proteins belonging to the monophyletic cluster mentioned above: Phe/Tyr23, Trp32 and Cys69 (coordinates correspond to the amino acid numbers in the E. coli protein). These residues are not conserved in the sequences of two viruses infecting Pseudomonas and Burkholderia, and only Cys corresponding to Cys69 is conserved in DnaC-like proteins in four phages/prophages related to P27. This suggests that these proteins interact with the viral helicase, not the host protein, although, of course, such a question cannot be decisively answered by sequence analysis alone.

\section{Construction of plasmids derived from Gifsy phages}

Using the host genomic DNA as a template, the Gifsy-1 replication-regulation region (which is identical to the corresponding Gifsy-2 sequence) was amplified and, after digestion with restriction endonucleases, ligated with a gene conferring resistance to tetracycline (see Methods for details). The construct efficiently transformed $E$. coli cells and was named pGifsy. We found that pGifsy was maintained in E. coli cells grown in Luria-Bertani medium at $37{ }^{\circ} \mathrm{C}$ with aeration, at a mean copy number of $\sim 50-55$ in wild-type bacteria (MG1655), which is a value comparable to that observed for $\lambda$ plasmids in cells cultured under similar conditions (also 50; Węgrzyn, 1995).

\section{DnaC $_{\text {Gifsy-independent replication of pGifsy }}$}

$O$ and $P$ are the only two genes necessary for replication and maintenance of $\lambda$ plasmids in $E$. coli cells (for a review see Węgrzyn \& Węgrzyn, 2002). However, as noted above, Gifsy phages use a helicase loader very similar to that of their host. Could the host DnaC be able to deliver the host helicase to the Gifsy origin? To answer this question, we constructed a plasmid devoid of the functional $d n a C_{\text {Gifsy }}$ gene. We found that this plasmid, pGifsyNoLoader, in which most of the dnaC $C_{\text {Gifsy }}$ gene was deleted, could transform E. coli cells and was stably maintained, though at a copy number lower ( $\sim 30-35$ in wild-type strain MG1655) than that of a plasmid with a functional $d n a C_{\text {Gifsy }}$ gene $(\sim 50-55)$.

This experiment suggests that the cellular DnaC protein can substitute for $\mathrm{DnaC}_{\text {Gifsy }}$. On the other hand, the 

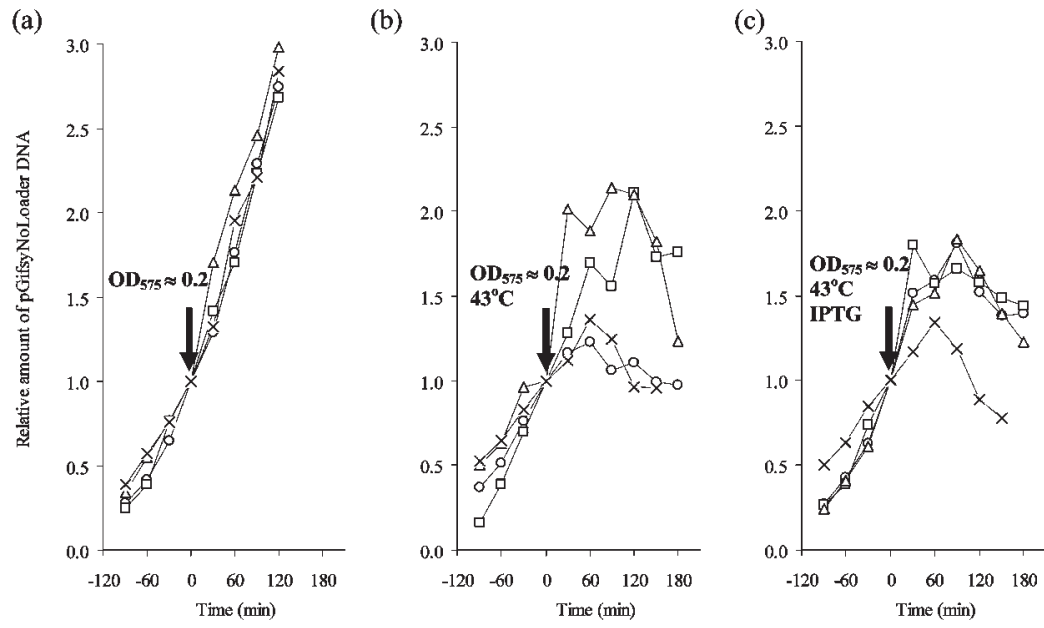

Fig. 3. Activity of the host and viral helicase loaders in pGifsyNoLoader replication in E. coli dnaC1(ts) cells. pGifsyNoLoader content in the cells was measured densitometrically at 30 min intervals in a dnaC1(ts) strain harbouring pQE30 (vector control, $\times$ ), or a plasmid carrying E. coli dnaC (pQE-EcoliDnaC, $\bigcirc$ ) or genes for E. coli K-12 prophage Rac (pQERacDnaC, $\triangle$ ) or $S$. enterica prophages Gifsy1/Gifsy-2 (pQE-GifsyDnaC, $\square$ ) helicase loaders under the control of $p_{\text {lac }}$ promoter. All plasmid content values are relative to time 0 , which corresponds to $\mathrm{OD}_{575} \sim 0.2(\mathrm{a}, \mathrm{b}, \mathrm{c})$, transfer of the culture from 30 to $43^{\circ} \mathrm{C}(\mathrm{b}, \mathrm{c})$, and promoter induction by addition of $1 \mathrm{mM}$ IPTG (c).

activity of the viral helicase loader delivered from pQEGifsyDnaC was not sufficient to suppress the dnaCl(ts) mutation, or to allow the survival of the host at $43{ }^{\circ} \mathrm{C}$, even in the presence of $1 \mathrm{mM}$ IPTG. In contrast, the presence of the E. coli gene on pQE-EcoliDnaC (even without promoter induction) allowed for continued growth of the dnaC1(ts) bacteria in liquid culture after the temperature upshift (data not shown; delivery of DnaC from a plasmid does not allow growth on plates at $43{ }^{\circ} \mathrm{C}$; Allen \& Kornberg, 1991).

The replication of pGifsyNoLoader in the $\mathrm{dnaCl}_{(\mathrm{ts})}$ strain stopped after temperature upshift (Fig. 3b, c), but this effect could be mitigated in the presence of a plasmid that carries either the co-specific $d n a C_{G i f s y}$ gene or a $d n a C$-like gene from the E. coli prophage Rac (which we called $d_{n a} C_{R a c}$ in the present work; Fig. 3b). Overexpression of these genes did not result in more efficient replication of pGifsyNoLoader (Fig. 3c). On the other hand, when the cells carried the E. coli dnaC expression plasmid, the effect on pGifsyNoLoader replication could only be seen when expression of the helicase loader was induced (Fig. 3c). However, when the helicase loaders were delivered from the pQE-based plasmids, the replication of pGifsyNoLoader continued for only about one round (Fig. 3b, c) and then stopped. In the control experiments, at $30{ }^{\circ} \mathrm{C}$, replication of pGifsyNoLoader continued as the bacteria divided in the presence of plasmid carrying genes encoding host DnaC and $\mathrm{DnaC}_{\text {Gifsy }}$ or $\mathrm{DnaC}_{\mathrm{Rac}}$.

Interestingly, replication of pGifsy was also stopped after transfer of the dnaCl(ts) host to $43{ }^{\circ} \mathrm{C}$ (Fig. 4). We investigated whether or not the arrest of pGifsy replication in $d n a C 1$ (ts) strains after temperature upshift was due to the general arrest of plasmid DNA replication after termination of host replication. Such a general arrest was unlikely, since the replication of Gifsy plasmids continued after host replication was halted by transferring dnaA46(ts) bacteria to $43{ }^{\circ} \mathrm{C}$ (Fig. 5). The effect of the temperature upshift on these bacteria should be similar to that on the $d_{n a C 1}(\mathrm{ts})$ strain: inability to initiate chromosomal replication. In the dnaA46(ts) strain, however, pGifsy replication continued even $200 \mathrm{~min}$ after the upshift (Fig. 5), while it stopped in the $d n a C 1$ (ts) strain after $\sim 60$ min (Fig. 4). Moreover, if such a general arrest occurred, it should have affected other lambdoid plasmids. Although wild-type $\lambda$ plasmids could not be introduced into the $d n a C 1$ (ts) strain, a so-called $\pi$ derivative (pKB2 $\pi$ ) could be introduced (data not shown). This is perhaps because the presence of the wild-type $\lambda \mathrm{P}$ is toxic for these cells. It is possible that wild-type $\lambda \mathrm{P}$ binds the DnaB protein so strongly that the mutated $\mathrm{DnaC}$ protein cannot deliver the helicase to the host origin. The $\lambda \pi$ plasmid carries a mutation in the $P$ gene which allows plasmid replication in strains deficient in the Hsp70 chaperone machine: the mutated $\mathrm{P}$ protein competes less efficiently

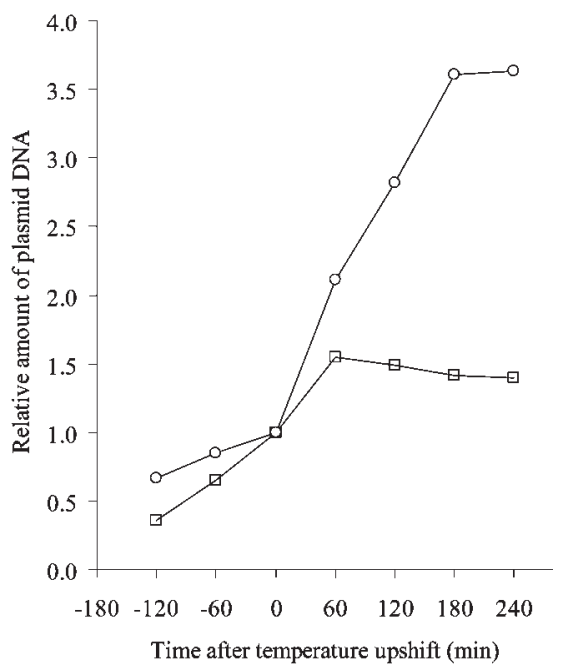

Fig. 4. Replication of plasmids derived from prophages Gifsy and phage $\lambda$ in $d n a C 1$ (ts) cells. The relative plasmid content in the cells was measured densitometrically at 60 min intervals in a dnaC1(ts) strain harbouring pGifsy ( $\square$ ) or pKB2 $\pi$ (a $\lambda$ plasmid, $\bigcirc$ ), before and after temperature upshift (time 0 ). 


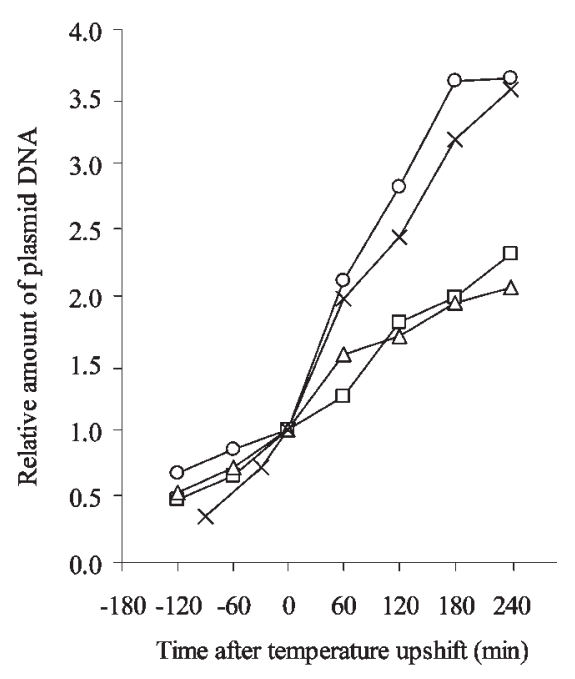

Fig. 5. Replication of Gifsy plasmids in dnaA46(ts) cells. The relative plasmid content in the cells was measured densitometrically at 60 min intervals in a dnaA46(ts) strain harbouring pGifsy $(\square)$, pGifsyNoLoader $(\triangle$ ), pKB2 $\pi$ (a $\lambda$ replicon, $\bigcirc$ ) or pQE30 (a pMB1 replicon, $\times$ ), before and after temperature upshift (time 0 ).

with the host DnaC protein for DnaB binding (Konieczny \& Marszalek, 1995). Our experiments showed that although the replication of pGifsy was arrested in dnaC1(ts) cells after temperature upshift, replication of pKB $2 \pi$ continued (Fig. 4).

The fact that replication of both pGifsyNoLoader and pGifsy stopped at $43{ }^{\circ} \mathrm{C}$ in the $d n a C 1$ (ts) bacteria suggests that $\mathrm{DnaC}_{\text {Gifsy }}$ forms heterocomplexes with the host DnaC, and these heterocomplexes are inactive for helicase loading after temperature upshift. If this is so, when the host DnaC is overexpressed, only a minority of heterocomplexes contain the protein that is inactivated at high temperature. Interference of the $\mathrm{DnaCl}(\mathrm{ts})$ protein in the heterocomplexes with the proper loading of the helicase at the Gifsy origin might explain why the suppression of the effects of the dnaC1(ts) mutation on pGifsyNoLoader and pGifsy replication by helicase loaders produced from another plasmid is only transient. This explanation should, however, be treated as highly speculative, since it is not clear how one can explain that replication of pGifsyNoLoader remains transient even when DnaC $_{\text {Gifsy }}$ is overexpressed. Moreover, if this explanation is true, it does not apply to host replication initiation, since dnaC1(ts) bacteria grow normally when E. coli DnaC is delivered from a plasmid, as mentioned above.

Transient replication of pGifsyNoLoader in cells overexpressing the phage helicase loader might, at least in part, result from the toxicity of overproduction of phage DnaClike proteins in $E$. coli cells. It has been shown that overproduction of E. coli DnaC inhibits bacterial growth (Allen \& Kornberg, 1991). $\lambda$ P protein, when overproduced, is also toxic to E. coli, via a mechanism that involves not only the inactivation of the DnaB helicase, but also impairment of the function of DnaA, the initiator of DNA replication from oriC (Datta et al., 2005a, b). We found that overproduction of $\mathrm{DnaC}_{\text {Gifsy }}$ from an overexpression plasmid pQE-GifsyDnaC (Fig. 6) was also toxic to E. coli (and so was the overexpression of its homologue, $\mathrm{DnaC}_{\mathrm{Rac}}$, from $\mathrm{pQE}-\mathrm{RacDnaC}$; data not shown). This result supports the hypothesis that in bacteria overproducing $\mathrm{DnaC}_{\text {Gifsy, }}$ the host helicase is trapped in DnaC $_{\text {Gifsy }}-$ DnaB and possibly DnaC $_{\text {Gifsy }}-$ DnaC $C_{\text {Ecoli }}-$ DnaB complexes, which are inactive in oriC replication. The toxicity could be alleviated in the presence of limited amounts of E. coli DnaB or DnaC proteins (Fig. 6). Overproduction of these host proteins did not affect the results (data not shown), suggesting that even low-level production is sufficient to mitigate the toxic effects of DnaC $_{\text {Gifsy }}$.

\section{Compatibility of plasmids derived from bacteriophage $\lambda$ and Gifsy prophages}

Sequence analysis suggests that the structure of iterons carried by the origin of replication of Gifsy phages is very similar to that of the iterons carried by phage $\lambda$. Also, both

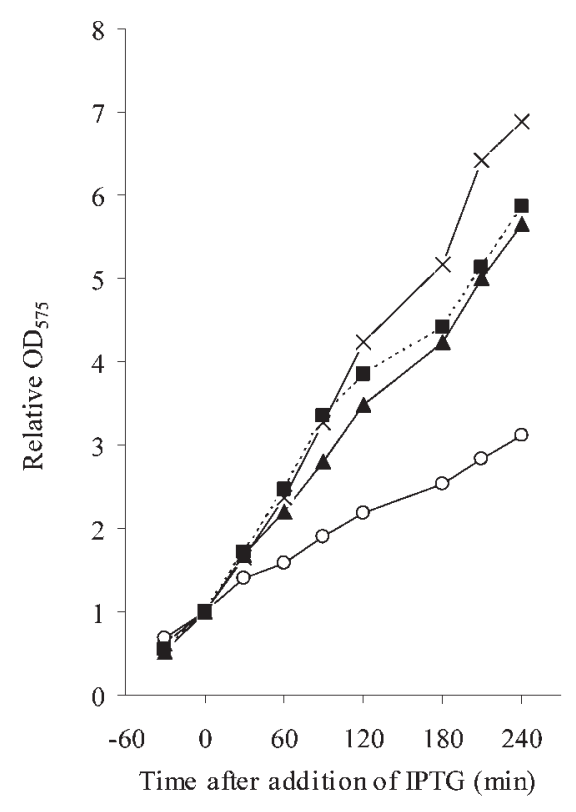

Fig. 6. Production of DnaB and DnaC alleviates the toxic effects of $\mathrm{P}_{\text {Gifsy }}$ on bacterial growth. The growth of $E$. coli XL1-Blue strain harbouring pQE30 (vector control, $\times$ ), pQE-GifsyDnaC (dnaC $C_{\text {Gifsy }}$ under an IPTG-inducible promoter, $\bigcirc$ ) or pQE-GifsyDnaC with pINB (carrying dnaC under a $p_{\text {ara }}$ promoter, $\mathbf{\square}$ ), or pQEGifsyDnaC with pINC (carrying $d n a B$ under a $p_{\text {ara }}$ promoter, $\mathbf{\Delta}$ ) was monitored by measuring $\mathrm{OD}_{575}$ relative to the optical density of the culture at the time of induction of $d n a C_{\text {Gifsy }}$ overexpression with $1 \mathrm{mM}$ IPTG (time 0). The figure shows results obtained in the absence of L-arabinose. Results obtained after induction of $p_{\text {ara }}$ were similar (data not shown). 
origins probably depend on a very similar repertoire of host factors for their replication. We therefore investigated if the plasmids derived from bacteriophage $\lambda$ and Gifsy prophages could be stably co-maintained in bacterial cells. We found that pGifsy (which carries a tetracycline-resistance gene) was incompatible with pCB104, a $\lambda$ plasmid carrying a gene for chloramphenicol acetyltranferase: out of 100 colonies formed by bacteria originally carrying both a $\lambda$ plasmid and pGifsy, but selected for growth on a plate containing only one antibiotic (chloramphenicol or tetracycline), none grew on the plates that also contained the other antibiotic. However, in the presence of $\mathrm{pQE}$ EcoliDnaC (which carries resistance for ampicillin; without addition of IPTG), both plasmids derived from lambdoid phages were compatible (100 colonies were tested). In cells carrying pQE-GifsyDnaC, on the other hand, the plasmids were weakly incompatible (without addition of IPTG, $77 \%$ of the cells grown on chloramphenicol were tetracycline resistant and $32 \%$ grown on tetracycline were chloramphenicol resistant). While the reasons for the incompatibility are not clear, these results provide an additional illustration of the inteference between the helicase loading of the lambdoid plasmids and the host chromosome. Such interference might arise from the competition of the loaders for the DnaB helicase, and from the formation of heterocomplexes of helicase loaders inactive in the initiation of chromosomal initiation.

\section{Involvement of molecular chaperones in pGifsy replication}

$\lambda \mathrm{P}$ protein binds very strongly to the host DnaB helicase and inhibits all its activities. The action of molecular chaperones DnaK and DnaJ, supported by the activity of GrpE, is necessary for rearrangement of the pre-primosomal complex and liberation of DnaB from $\lambda$ P-mediated inhibition (Liberek et al., 1988; for review see Węgrzyn \& Węgrzyn, 2002). DnaC-DnaB complexes are significantly weaker than $\lambda$ P-DnaB complexes (Wickner, 1979; Wold et al., 1982; Mallory et al., 1990; Konieczny \& Marszałek, 1995), and it appears that DnaC dissociates from DnaB without the assistance of molecular chaperones. The fact that host DnaC can act instead of DnaC Gifsy $_{\text {in }}$ pGifsyNoLoader replication does not necessarily imply that the interaction of $\mathrm{DnaC}_{\text {Gifsy }}$ with $\mathrm{DnaB}$ is similarly weak. Indeed, selective pressure to redirect the host helicase to the viral origin has been put forward as an explanation for the strong $\lambda \mathrm{P}$-host DnaB interaction, and all lambdoid phages are, conceivably, under similar pressure in this respect. We therefore investigated the requirement for molecular chaperones in replication of Gifsy-derived plasmid DNA.

We found that, unlike $\lambda$ plasmids (Węgrzyn et al., 1996), pGifsy effectively transformed E. coli dnaK756 and dnaJ259 mutants at $30{ }^{\circ} \mathrm{C}$ (data not shown). This suggests that the activity of the Hsp70 chaperone machine is not required for oriGifsy replication. It is still possible that molecular chaperones play some role in Gifsy replication, but this would be difficult to demonstrate in vivo, considering that host DnaC can function in the delivery of the helicase to the Gifsy origin.

\section{Stringent control of pGifsy replication}

Replication of plasmids derived from bacteriophage $\lambda$ is inhibited in amino acid-starved wild-type cells (i.e. during the stringent response) but not in relA mutants (i.e. during the relaxed response; for a review see Węgrzyn, 1999). The replication can proceed in the absence of protein synthesis, due to formation of a stable replication complex, which is inherited by one of two daughter plasmid copies after each replication round, and can function in subsequent replication events (Węgrzyn \& Węgrzyn, 2001). Under the stringent response, $\lambda$ plasmid DNA replication is arrested due to a lack of activity of the $\lambda p_{\mathrm{R}}$ promoter, necessary for the transcriptional activation of the origin (Wegrzyn \& Węgrzyn, 2001). The activity of this promoter is regulated by the specific nucleotide produced in amino acid-starved cells, guanosine $5^{\prime}$-diphosphate-3'-diphosphate (ppGpp; Wróbel et al., 1998a). In relA bacteria [which do not have (p)ppGpp synthetase I activity], ppGpp does not accumulate during amino acid starvation, and $\lambda$ plasmid replication continues even though new replication complexes are not formed.

We found that, similar to $\lambda$ plasmids and plasmids derived from the Rac prophage of E. coli K-12 (Potrykus et al., 2000), the replication of pGifsy continued in the amino acid-starved relA cells. We observed a moderate increase in the copy number of pGifsy during the relaxed response, but not during the stringent response (Fig. 7), which implies that replication of pGifsy is under stringent control, similar to the replication of $\lambda$ plasmids. During the stringent response, plasmid replication appeared to be completely stopped, which resulted in the observed decrease in the amount of plasmid DNA relative to bacterial cell mass (determined by $\mathrm{OD}_{575}$ measurement; under these experimental conditions, the culture $\mathrm{OD}_{575}$ slowly increased, from $\sim 0.2$ at the onset of starvation to $\sim 0.4$ after $5 \mathrm{~h}$ ).

\section{DISCUSSION}

In this report, we demonstrate that a DNA fragment of prophages Gifsy-1 and Gifsy-2 of S. enterica serovar Typhimurium, which in genetic organization is very similar to the replication region of bacteriophage $\lambda$, can replicate autonomously in E. coli cells. The origin of replication of pGifsy appears to be located in the middle of the $O_{\text {Gifsy }}$ gene, which is necessary for plasmid replication, and likely encodes a replication initiator protein.

\section{Helicase loaders of lambdoid phages}

The analysis of the replication regions of lambdoid phages indicates that four types of these regions can be identified, 


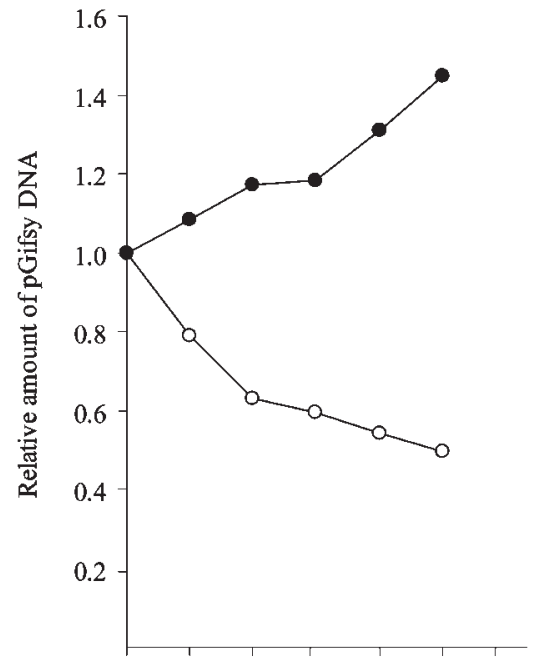

$\begin{array}{llllll}60 & 120 & 180 & 240 & 300 & 360\end{array}$

Time after induction of aa starvation ( $\mathrm{min}$ )

Fig. 7. Amplification of pGifsy during the relaxed response in $E$. coli. The plasmid content was measured at 60 min intervals in relA $A^{+}($strain $\mathrm{CP} 78, \bigcirc)$ and relA $(\mathrm{CP} 79,0)$ bacteria growing in a minimal medium relative to that at the onset of isoleucine starvation induced by addition of L-valine (time 0 ). aa, amino acid.

depending on the way the helicase is probably brought to the origin: (i) replicons using a homologue of phage $\lambda \mathrm{P}$ protein; (ii) those using a loader similar to the enterobacterial DnaC which transports the host helicase; (iii) those using such a protein but probably to transport a phage helicase encoded by a neighbouring gene; and (iv) phages that have a gene for a helicase but not a loader. The prophages carrying a dnaC-like gene are particularly common in the sequenced genomes of pathogenic bacteria (Fig. 2). It is unclear if the two types of helicase loaders are related: $\lambda \mathrm{P}$ and DnaC show no apparent sequence similarity, and the predicted secondary structure of the two proteins does not show any common pattern. Perhaps this question can be answered when the structure of both proteins is resolved.

Although Gifsy is similar to $\lambda$ in that it uses the host helicase and a phage-encoded helicase loader, the fact that the Gifsy loader can be substituted by the host-encoded DnaC protein is a significant difference between the two replicons. It is difficult to say at this point if this functional substitution allows for a drastically reduced requirement for molecular chaperones DnaK and DnaJ in Gifsy replication initiation. The other possibility is that the ${ }_{\text {DnaC }}$ Gifsy $_{-}-$DnaB interaction itself resembles the DnaCDnaB interaction, and that the activity of molecular chaperones is not necessary to free the helicase from the phage loader during recruitment at the origin of replication. Host DnaC leaves the initiation complex immediately after helicase loading, a process accompanied by ATP hydrolysis, freeing DnaB from inhibition (Wahle et al., 1989a, b). Whether phage DnaC-like proteins function similarly could be answered by in vitro experiments.

In $\lambda$ replication, molecular chaperones are responsible for the rearrangement of the pre-primosomal complex and liberation of DnaB helicase from $\lambda \mathrm{P}$-mediated inhibition (Węgrzyn \& Węgrzyn, 2002). However, a substitution in the $P$ gene (a $\pi$ mutation) allows for $\lambda$ replication in $d n a K$ and dnaJ mutant hosts (Konieczny \& Marszalek, 1995). The $\lambda P \pi$ gene product interacts with $\mathrm{DnaB}$, significantly more weakly than the wild-type $\lambda \mathrm{P}$ protein (Konieczny \& Marszalek, 1995). Our experiments suggest that the $\pi$ mutation allows the $\lambda$ plasmid to be maintained in dnaC1(ts) bacteria. The fact that derivatives of plasmids encoding a loader with weaker binding to the helicase can be readily obtained suggests that the gene experiences selective pressure, so that the phage loader can compete more successfully with the host DnaC protein for DnaB (Konieczny \& Marszalek, 1995).

Why is efficient binding of the host helicase advantageous for the virus? Perhaps it is important to prevent the replication of other replicons in the cell that depend on host DnaB (the chromosome, plasmids and competing viruses). Phage $\lambda$ also uses other mechanisms to stall host replication (Kędzierska et al., 2003). This might explain why the viral DnaC-like proteins, despite high similarity to the host protein, are inactive in host replication, and indeed toxic when overproduced. The results of our experiments on the incompatibility between pGifsy and $\lambda$ plasmid suggest that moderate levels of the Gifsy helicase loader help to prevent plasmid loss (although not as efficiently as the host helicase loader), which is most likely caused by the competition for the host helicase between the lambdoid plasmids and the bacterial chromosome. This is consistent with the hypothesis of formation of heterocomplexes between $\mathrm{DnaC}_{\mathrm{Gifs}}$ and DnaC which can deliver the helicase to oriC, as long as the host DnaC is present in the heterocomplex. According to this interpretation, $\mathrm{DnaC}_{\text {Gifsy }}$ homocomplexes (proposed to be abundant when the level of the protein is high, e.g., during the lytic cycle or when the protein is overexpressed from a plasmid) bound to DnaB are not active in the initiation of chromosomal replication. Additional mechan-

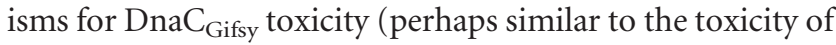
$\lambda$ P; Datta et al., 2005a, b) may come into play.

It would be interesting to see if the loader in the phages that encode a viral helicase also plays a role in binding a helicase of the host to stop replication of the competing DNA molecules. Such binding could be a pre-adaptation for the development of a lambdoid replicon in which the host helicase is used instead of the phage-encoded protein, and provides a possible scenario for the origin of helicase loader proteins.

\section{Evolution of helicase loading in bacteria}

Although it is possible that helicase loaders are present in bacterial species whose genomic sequences have not yet 
been obtained, so far, helicase loaders have only been identified in bacteria related to E. coli and Bacillus subtilis. In Gram-positive bacteria, two proteins are involved in loading the replicative helicase (which in B. subtilis has been named DnaC): DnaB and DnaI (Velten et al., 2003). B. subtilis DnaB does not seem to have known homologues outside the Firmicutes that could be found in BLAST searches of the GenBank database. B. subtilis DnaI, on the other hand, contains an ATP-binding domain homologous to that present in E. coli DnaC, and interacts with Bacillus helicase (Soultanas, 2002), forming a helicase ${ }_{6}-$

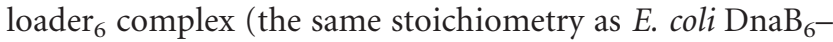
$\mathrm{DnaC}_{6}$; Ioannou et al., 2006). Proteins similar to B. subtilis DnaI are encoded in replication modules of bacterial viruses infecting Gram-positive bacteria (data not shown).

In other words, analysis of fully sequenced genomes shows that numerous bacteria lack DnaC-like and DnaB/I-type helicase loaders. This may mean that: (i) these organisms encode a different type of helicase loader; (ii) that they have evolved so that such factors are no longer required for initiating DNA replication; or (iii) that the helicase-loading proteins are a late introduction into the bacterial replication initiation system.

Biochemical evidence suggests that the first possibility is unlikely, at least for some species related to E. coli: in Pseudomonas species, DnaB protein apparently acts without any accessory protein (Caspi et al., 2001). The fact that most bacterial lineages are devoid of the DnaC homologue is not consistent with the hypothesis of an ancient origin for helicase loading: the wide-ranging loss of an important element of the cellular machinery is not likely. This reasoning leads to the proposal that the enterobacterial dnaT-dnaC genes and the gene for helicase loader in Gram-positive bacteria were acquired relatively recently from lambdoid replicons, most likely from a defective lambdoid prophage (Wróbel \& Węgrzyn, 2002). Low-level expression, perhaps after several mutations attenuating the toxicity, might have permitted the adaptation of the viral loader for the host replication initiation machinery. Subsequently, it might have allowed for at least a shortterm competitive advantage against the toxic effect of viral helicase loaders. The ensuing molecular arms race could have resulted in the development of a $\lambda \mathrm{P}$ protein that binds DnaB very strongly, but requires the action of molecular chaperones to unblock helicase activity. The question whether viral DnaC-like proteins bind the helicase more strongly than the loader adapted by the host, as a result of such a molecular arms race, remains to be answered by in vitro experiments.

Perhaps the most interesting aspect of the hypothesis of dnaC acquisition from lambdoid prophages is the continued presence of the gene in the extremely reduced genomes of Buchnera, intracellular endosymbionts of aphids, as demonstrated by the results of our database searches. Buchnera genomes are about one-seventh of the E. coli genome and have experienced severe loss of coding sequences, including genes considered essential for bacterial cells, e.g. recA (Shigenobu et al., 2000). Reconstruction of the core genome of the last common ancestor of $E$. coli, Klebsiella pneumoniae, Yersinia pestis and Vibrio cholerae indicates that $d n a C$ and $d n a T$ may be the only two genes added to the genome of the Escherichia-Buchnera ancestor that have been subsequently conserved in the Buchnera lineage (Moran \& Mira, 2001). The evolutionary scenario we propose is consistent with the view that the last common ancestor of Buchnera and Escherichia was more recent than the divergence of other enterobacterial lineages, in particular, the Yersinia lineage (Lerat et al., 2003). However, it must be noted that the issue of the phylogeny of Buchnera (and other endosymbionts) is controversial (Lerat et al., 2003; Canback et al., 2004). The fact that, at least in one lineage of endosymbionts, reductive evolution did not affect the gene for the helicase loader, which is apparently not needed by closely related enterobacteria, such as Yersinia, suggests that once the replication initiation machinery has been adapted to new members, the reversal of the process is difficult.

The hypothesis that cellular proteins involved in DNA metabolism have a viral or plasmid origin is not new. It has been proposed (Forterre, 1999) to explain the apparent lack of homology between the bacterial, archeal and eukaryotic proteins involved in the processing of DNA (as opposed, for example, to the genes involved in translation). This hypothesis postulates the replacement of genes that coded for such enzymes and originated before the divergence of the three lineages by viral/plasmid genes. In other words, the idea is to explain the very deep phylogenetic relationships (or the lack of them) between the genes of the three lineages as an alternative to the hypothesis according to which the lineages separated when RNA, not DNA, still carried out the information storage task in the cell (Mushegian \& Koonin, 1996). As support for his hypothesis, Forterre (1999) has noted: (i) high similarity between many viral and plasmid proteins and bacterial replication proteins; and (ii) that non-orthologous gene displacement of many replication and recombination proteins has been observed in experimental conditions. We do not believe that the latter is very relevant (although it is suggestive), since the selection conditions in the laboratory are very different from those in the natural environment. Another argument (Iyer et al., 2005) against the displacement hypothesis is the lack of evidence that any gene central to DNA replication (e.g. those for the main replicative primase, helicase, DNA clamp, DNA ligase or DNA polymerase) has ever been displaced by the viral or plasmid gene within any lineage (the emphasis is ours). We agree that the central DNA replication machinery, once the individual components are fine-tuned, is most likely refractory to displacement. This is equivalent to saying that cells in which such co-opting occurs have no selective advantage over the wild-type competition. Of course, this view can only be falsified when such displacement is observed in at least one of the 
lineages. However, the stress here should be put on the fact that the machinery first needs to be fine-tuned to be refractive, and the fact that the displacement has not been observed within the extant clades is not relevant to possible displacements of ancient, possibly less-adapted systems, at the time of lineage divergence.

Unfortunately, the hypothesis of the viral origin of helicase loaders in enterobacteria and Firmicutes is of little use to resolve this debate. It is our argument that the helicase loaders appear to be rather peripheral members of the DNA replication machinery. We propose a scenario of coopting new peripheral players to the otherwise fine-tuned machinery under very strong selective pressure (first suppression of toxic effects, then competition between the host and virus replication origins for the host helicase), rather than a scenario of displacement.

The observed parallels between the mechanism of helicase loading in model organisms - bacteriophage $\lambda$, E. coli and $B$. subtilis - have attracted even more attention after the observation of the interaction between the $\mathrm{Mcm} 2-7$ helicase hexamer and a protein similar to DnaC of E. coli, Cdc6 (Davey et al., 2002; Maiorano et al., 2006), important for replication initiation in yeast. However, although Cdc6 and E. coli DnaC both belong to the AAA + family of ATPases, this protein family is very large. In the case of the Firmicutes and enterobacteria, the same stoichiometry of the helicase-loader complex, and the relationships between the bacterial and viral proteins (with lambdoid phages as a bridge linking two bacterial lineages) suggest that the most recent common ancestor of these proteins could have been a helicase loader. It is not clear if this is the case for the ancestor of E. coli DnaC and yeast Cdc6. We are not aware of any results that would suggest that Cdc6 interacts with the helicase in a fashion similar to the bacterial helicase loaders (a hexamer of helicase loaders interacting with the helicase hexamer before DNA binding). Until this is demonstrated, it is doubtful whether the E. coli DnaChelicase or Bacillus DnaI-DnaB-helicase systems provide relevant bacterial models for replication initiation in eukaryotes.

The research on helicase loading in model organisms has led historically to many important discoveries (e.g. it helped in the discovery of molecular chaperones; Yochem et al., 1978; Liberek et al., 1988). It now appears possible that the current models of the initiation of chromosomal DNA replication may be relevant only to bacteria closely related to the model organisms E. coli and Bacillus. It is necessary to shift our attention to other bacterial species so that general mechanisms can be proposed.

\section{ACKNOWLEDGEMENTS}

This work was supported by the Polish Ministry of Science and Higher Education (grants 2 P04A 025 27, N301 122 31/3747 and 726PRUE-2005-7), the European Union (Structural Funds Z/2.22/II/ 2.6/002/05), and the Foundation for Polish Science (B. W.). We appreciate the insights and comments of the Editor (Dr Laurent Jannière) and the anonymous reviewer.

\section{REFERENCES}

Abascal, F., Zardoya, R. \& Posada, D. (2005). ProtTest: selection of best-fit models of protein evolution. Bioinformatics 21, 2104-2105.

Allen, G. C. \& Kornberg, A. (1991). Fine balance in the regulation of DnaB helicase by DnaC protein in replication in Escherichia coli. J Biol Chem 266, 22096-22101.

Boonsombat, R., Yeh, S., Milne, A. \& Sandler, S. J. (2006). A novel dnaC mutation that suppresses priB rep mutant phenotypes in Escherichia coli K-12. Mol Microbiol 60, 973-983.

Boyd, A. C. \& Sherratt, D. J. (1995). The CLIP plasmids: versatile cloning vectors based on the bacteriophage $\lambda$ origin of replication. Gene 153, 57-62.

Brussow, H., Canchaya, C. \& Hardt, W. D. (2004). Phages and the evolution of bacterial pathogens: from genomic rearrangements to lysogenic conversion. Microbiol Mol Biol Rev 68, 560-602.

Bullock, W. O., Fernandez, J. M. \& Short, J. M. (1987). XL1-Blue: high efficiency plasmid transforming recA Escherichia coli strain with betagalactosidase selection. Biotechniques 5, 376-378.

Canback, B., Tamas, I. \& Anderson, S. G. E. (2004). A phylogenomic study of endosymbiotic bacteria. Mol Biol Evol 21, 1110-1122.

Caspi, R., Pacek, M., Consiglieri, G., Helinski, D. R., Toukdarian, A. \& Konieczny, I. (2001). A broad host range replicon with different requirements for replication initiation in three bacterial species. EMBO J 20, 3262-3271.

Clark, M. A., Moran, N. A. \& Baumann, P. (1999). Sequence evolution in bacterial endosymbionts having extreme base compositions. Mol Biol Evol 16, 1586-1598.

Coombes, B. K., Wickham, M. E., Brown, N. F., Lemire, S., Bossi, L., Hsiao, W. W. L., Brinkman, F. S. L. \& Finlay, B. B. (2005). Genetic and molecular analysis of GogB, a phage encoded type III-secreted substrate in Salmonella enterica serovar Typhimurium with autonomous expression from its associated phage. J Mol Biol 348, 817-830.

Datta, I., Banik-Maiti, S., Adhikari, L., Sau, S., Das, N. \& Manda, N. C. (2005a). The mutation that makes Escherichia coli resistant to $\lambda \mathrm{P}$ gene-mediated host lethality is located within the DNA initiator gene dnaA of the bacterium. J Biochem Mol Biol 38, 89-96.

Datta, I., Sau, S., Sil, A. K. \& Mandal, N. C. (2005b). The bacteriophage $\lambda$ DNA replication protein P inhibits the oriC DNA- and ATP-binding functions of the DNA replication initiator protein DnaA of Escherichia coli. J Biochem Mol Biol 38, 97-103.

Davey, M. J., Fang, L., Mclnerney, P., Georgescu, R. E. \& O’Donnell, M. (2002). The DnaC helicase loader is a dual ATP/ADP switch protein. EMBO J 21, 3148-3159.

De Groote, M. A., Ochsner, U. A., Shiloh, M. U., Nathan, C., Mccord, J. M., Dinauer, M. C., Libby, S. J., Vazquez-Torres, A., Xu, Y. \& Fang, F. C. (1997). Periplasmic superoxide dismutase protects Salmonella from products of phagocyte NADPH-oxidase and nitric oxide synthase. Proc Natl Acad Sci U S A 94, 13997-14001.

Dodd, I. B. \& Egan, J. B. (1987). Systematic method for the detection of potential $\lambda$ cro-like DNA-binding regions in proteins. $J$ Mol Biol 194, 557-564.

Dodd, I. B. \& Egan, J. B. (1990). Improved detection of helix-turnhelix DNA-binding motifs in protein sequences. Nucleic Acids Res 18, 5019-5026.

Fang, F. C., Degroote, M. A., Foster, J. W., Baumler, A. J., Ochsner, U., Testerman, T., Bearson, S., Giard, J., Xu, Y. \& other authors (1999). 
Virulent Salmonella Typhimurium has two periplasmic $\mathrm{Cu}, \mathrm{Zn}$ superoxide dismutases. Proc Natl Acad Sci U S A 96, 7502-7507.

Farrant, J. L., Sansone, A., Canvin, J. R., Pallen, M. J., Langford, P. R., Wallis, T. S., Dougan, G. \& Kroll, J. S. (1997). Bacterial copper- and zinc-cofactored superoxide dismutase contributes to the pathogenesis of systemic salmonellosis. Mol Microbiol 25, 785-796.

Felsenstein, J. (2005). PHYLIP (Phylogenetic Inference Package), 3.6. Distributed by the author. Department of Genome Sciences. University of Washington, Seattle.

Figueroa-Bossi, N. \& Bossi, L. (1999). Inducible prophages contribute to Salmonella virulence in mice. Mol Microbiol 33, 167-176.

Figueroa-Bossi, N., Uzzau, S., Maloriol, D. \& Bossi, L. (2001). Variable assortment of prophages provides a transferable repertoire of pathogenic determinants in Salmonella. Mol Microbiol 39, 260-271.

Fiil, N. \& Friesen, J. D. (1968). Isolation of relaxed mutants of Escherichia coli. J Bacteriol 95, 729-731.

Forterre, P. (1999). Displacement of cellular proteins by functional analogues from plasmid or viruses could explain puzzling phylogenies of many DNA informational proteins. Mol Microbiol 33, 457-465.

Friedman, D. I. \& Court, D. L. (2001). Bacteriophage $\lambda$ : alive and well and still doing its thing. Curr Opin Microbiol 4, 201-207.

Georgopoulos, C. P. (1977). A new bacterial gene (groPC) which affects DNA replication. Mol Gen Genet 151, 35-39.

Georgopoulos, C. \& Herskovitz, I. (1971). Escherichia coli mutants blocked in $\lambda$ DNA synthesis. In The Bacteriophage $\lambda$, pp. 553-564. Edited by A. D. Hershey. Cold Spring Harbor, NY: Cold Spring Harbor Laboratory.

Heller, R. C. \& Marians, K. J. (2005). The disposition of nascent strands at stalled replication forks dictates the pathway of replisome loading during restart. Mol Cell 17, 733-743.

Herold, S., Karch, H. \& Schmidt, H. (2004). Shiga toxin-encoding bacteriophages - genomes in motion. Int J Med Microbiol 294, 115121.

Ho, T. D., Figueroa-Bossi, N., Wang, M., Uzzau, S., Bossi, L. \& Slauch, J. M. (2002). Identification of GtgE, a novel virulence factor encoded on the Gifsy-2 bacteriophage of Salmonella enterica serovar Typhimurium. J Bacteriol 184, 5234-5239.

Ioannou, C., Schaeffer, P. M., Dixon, N. E. \& Soultanas, P. (2006). Helicase binding to DnaI exposes a cryptic DNA-binding site during helicase loading in Bacillus subtilis. Nucleic Acids Res 34, 5247-5258.

Iyer, L. M., Koonin, E. V., Leipe, D. D. \& Aravind, L. (2005). Origin and evolution of the archaeo-eukaryotic primase superfamily and related palm-domain proteins: structural insights and new members. Nucleic Acids Res 33, 3875-3896.

Jensen, K. F. (1993). The Escherichia coli 'wild types' W3110 and MG1655 have rph frame shift mutation that leads to pyrimidine starvation due to low pyrE expression levels. J Bacteriol 175, 34013407.

Jones, D. T., Taylor, W. R. \& Thornton, J. M. (1992). The rapid generation of mutation data matrices from protein sequences. Comput Appl Biosci 8, 275-282.

Kędzierska, B., Glinkowska, M., Iwanicki, A., Obuchowski, M., Sojka, P. Thomas, M. S. \& Węgrzyn, G. (2003). Toxicity of the bacteriophage $\lambda$ cII gene product to Escherichia coli arises from inhibition of host cell DNA replication. Virology 4313, 622-628.

Konieczny, I. \& Marszalek, J. (1995). The requirement for molecular chaperones in $\lambda$ DNA replication is reduced by the mutation $\pi$ in $\lambda P$ gene, which weakens the interaction between $\lambda \mathrm{P}$ protein and DnaB helicase. J Biol Chem 270, 9792-9799.
Krishnakumar, R., Craig, M., Imlay, J. A. \& Slauch, J. M. (2004). Differences in enzymatic properties allow SodCI but not SodCII to contribute to virulence in Salmonella enterica serovar Typhimurium strain 14028. J Bacteriol 186, 5230-5238.

Kur, J., Gorska, I. \& Taylor, K. (1987). Escherichia coli dnaA initiation function is required for replication of plasmids derived from coliphage lambda. J Mol Biol 198, 203-210.

Lawley, T. D., Chan, K., Thompson, L. J., Kim, C. C., Govoni, G. R. \& Monack, D. M. (2006). Genome-wide screen for Salmonella genes required for long-term systemic infection of the mouse. PLoS Pathog 2, el1.

Lerat, E., Daubin, V. \& Moran, N. A. (2003). From gene trees to organismal phylogeny in prokaryotes: the case of the $\gamma$-proteobacteria. PLoS Biol 1, e19.

Liberek, K., Georgopoulos, C. \& Zylicz, M. (1988). Role of the Escherichia coli DnaK and DnaJ heat shock proteins in the initiation of bacteriophage $\lambda$ DNA replication. Proc Natl Acad Sci U S A 85, 6632-6636.

Lipińska, B., Fayet, O., Baird, L. \& Georgopoulos, C. (1989). Identification, characterization, and mapping of the Escherichia coli $h \operatorname{trA}$ gene, whose product is essential for bacterial growth only at elevated temperatures. J Bacteriol 171, 1574-1584.

Ludlam, A. V., McNatt, M. W., Carr, K. M. \& Kaguni, J. M. (2001). Essential amino acids of Escherichia coli DnaC protein in an Nterminal domain interact with DnaB helicase. J Biol Chem 276, 27345-27353.

Mallory, J. B., Alfano, C. \& McMacken, R. (1990). Host virus interactions in the initiation of bacteriophage $\lambda$ DNA replication. Recruitment of Escherichia coli DnaB helicase by $\lambda \mathrm{P}$ replication protein.. J Biol Chem 265, 13297-13307.

Maiorano, D., Lutzmann, M. \& Mechali, M. (2006). MCM proteins and DNA replication. Curr Opin Cell Biol 18, 130-136.

McClelland, M., Sanderson, K. E., Spieth, J., Clifton, S. W., Latreille, P., Courtney, L., Porwollik, S., Ali, J., Dante, M. \& other authors (2001). Complete genome sequence of Salmonella enterica serovar Typhimurium LT2. Nature 413, 852-856.

Miao, E. A. \& Miller, S. I. (2000). A conserved amino acid sequence directing intracellular type III secretion by Salmonella Typhimurium. Proc Natl Acad Sci U S A 97, 7539-7544.

Moran, N. A. \& Mira, A. (2001). The process of genome shrinkage in the obligate symbiont Buchnera aphidicola. Genome Biol 2, RESEARCH0054.

Murotsu, T. \& Matsubara, K. (1980). Role of an autorepression system in the control of $\lambda \mathrm{dv}$ plasmid copy number and incompatibility. Mol Gen Genet 179, 509-519.

Mushegian, A. R. \& Koonin, E. V. (1996). A minimal gene set for cellular life derived by comparison of complete bacterial genomes. Proc Natl Acad Sci U S A 93, 10268-10271.

Nakayama, N., Bond, M. W., Miyajima, A., Koborin, J. \& Arai, K. (1987). Structure of Escherichia coli dnaC. J Biol Chem 262, 1047510480 .

Pearson, W. R. (1996). Effective protein sequence comparison. Methods Enzymol 266, 227-258.

Potrykus, K., Wrobel, B., Wegrzyn, A. \& Wegrzyn, G. (2000). Replication of oriJ-based plasmid DNA during the stringent and relaxed responses of Escherichia coli. Plasmid 44, 111-126.

Potrykus, K., Baranska, S., Węgrzyn, A. \& Węgrzyn, G. (2002). Composition of the $\lambda$ plasmid heritable replication complex. Biochem $J$ 364, 857-862.

Ptashne, M. (1992). A Genetic Switch: Phage $\lambda$ and Higher Organisms. Cambridge, MA: Cell Press and Blackwell Scientific. 
Rice, P., Longden, I. \& Bleasby, A. (2000). EMBoss: the European Molecular Biology Open Software Suite. Trends Genet 16, 276-277.

Sandler, S. J. (2000). Multiple genetic pathways for restarting DNA replication forks in Escherichia coli K-12. Genetics 155, 487-497.

Sanjuán, R. \& Wróbel, B. (2005). Weighted least-squares likelihood ratio test for branch testing in phylogenies reconstructed from distance measures. Syst Biol 54, 218-229.

Sansone, A., Watson, P. R., Wallis, T. S., Langford, P. R. \& Kroll, J. S. (2002). The role of two periplasmic copper- and zinc-cofactored superoxide dismutases in the virulence of Salmonella choleraesuis. Microbiology 148, 719-726.

Schicklmaier, P. \& Schmieger, H. (1997). Sequence comparison of the genes for immunity, DNA replication, and cell lysis of the P22related Salmonella phages ES18 and L. Gene 195, 93-100.

Shigenobu, S., Watanabe, H., Hattori, M., Sakaki, Y. \& Ishikawa, H. (2000). Genome sequence of the endocellular bacterial symbiont of aphids Buchnera sp. APS. Nature 407, 81-86.

Słomińska, M., Konopa, G., Barańska, S., Węgrzyn, G. \& Węgrzyn, A. (2003). Interplay between DnaA and SeqA proteins during regulation of bacteriophage $\lambda p_{\mathrm{R}}$ promoter activity. J Mol Biol 329, 59-68.

Soultanas, P. (2002). A functional interaction between the putative primosomal protein DnaI and the main replicative DNA helicase DnaB in Bacillus. Nucleic Acids Res 30, 966-974.

Stanley, T. L., Ellermeier, C. D. \& Slauch, J. M. (2000). Tissue-specific gene expression identifies a gene in the lysogenic phage Gifsy-1 that affects Salmonella enterica serovar Typhimurium survival in Peyer's patches. J Bacteriol 182, 4406-4413.

Taylor, K. \& Węgrzyn, G. (1995). Replication of coliphage $\lambda$ DNA. FEMS Microbiol Rev 17, 109-119.

Thomas, M. S. \& Glass, R. E. (1991). Escherichia coli rpoA mutation which impairs transcription from positively regulated systems. Mol Microbiol 5, 2719-2725.

Tsurimoto, T. \& Matsubara, K. (1981a). Purified bacteriophage $\lambda \mathrm{O}$ protein binds to four repeating sequences at the $\lambda$ replication origin. Nucleic Acids Res 9, 1789-1799.

Tsurimoto, T. \& Matsubara, K. (1981b). Purification of bacteriophage $\lambda \mathrm{O}$ protein that specifically binds to the origin of replication. Mol Gen Genet 181, 325-331.

Velten, M., McGovern, S., Marsin, S., Ehrlich, S. D., Noirot, P. \& Polard, P. (2003). A two-protein strategy for the functional loading of a cellular replicative DNA helicase. Mol Cell 11, 1009-1020.

Wahle, E., Lasken, R. S. \& Kornberg, A. (1989a). The dnaB-dnaC replication protein complex of Escherichia coli. I. Formation and properties. J Biol Chem 264, 2463-2468.
Wahle, E., Lasken, R. S. \& Kornberg, A. (1989b). The dnaB-dnaC replication protein complex of Escherichia coli. II. Role of the complex in mobilizing dnaB functions. J Biol Chem 264, 2469-2475.

Węgrzyn, G. (1995). Amplification of $\lambda$ plasmids in Escherichia coli relA mutants. J Biotechnol 43, 139-143.

Węgrzyn, G. (1999). Replication of plasmids during bacterial response to amino acid starvation. Plasmid 41, 1-16.

Węgrzyn, A. \& Węgrzyn, G. (2001). Inheritance of the replication complex: a unique or common phenomenon in the control of DNA replication?. Arch Microbiol 175, 86-93.

Węgrzyn, G. \& Węgrzyn, A. (2002). Stress responses and replication of plasmids in bacterial cells. Microb Cell Fact 1, 2.

Węgrzyn, G. \& Węgrzyn, A. (2005). Genetic switches during bacteriophage $\lambda$ development. Prog Nucleic Acid Res Mol Biol 79, 1-48.

Węgrzyn, G., Neubauer, P., Krueger, S., Hecker, M. \& Taylor, K. (1991). Stringent control of replication of plasmids derived from coliphage $\lambda$. Mol Gen Genet 225, 94-98.

Węgrzyn, G., Węgrzyn, A., Pankiewicz, A. \& Taylor, K. (1996). Allele specificity of the Escherichia coli dnaA gene function in the replication of plasmids derived from phage $\lambda$. Mol Gen Genet 252, 580-586.

Wickner, S. H. (1979). DNA replication proteins of Escherichia coli and phage $\lambda$. Cold Spring Harb Symp Quant Biol 43, 303-310.

Wold, M. S., Mallory, J. B., Roberts, J. D., LeBowitz, J. H. \& McMacken, R. (1982). Initiation of bacteriophage $\lambda$ DNA replication in vitro with purified $\lambda$ replication proteins. Proc Natl Acad Sci U S A 79, 6176-6180.

Worley, M. J., Ching, K. H. \& Heffron, F. (2000). Salmonella SsrB activates a global regulon of horizontally acquired genes. Mol Microbiol 36, 749-761.

Wróbel, B. \& Węgrzyn, G. (2002). Evolution of lambdoid replication modules. Virus Genes 24, 163-171.

Wróbel, B., Murphy, H., Cashel, M. \& Wegrzyn, G. (1998a). Guanosine tetraphosphate (ppGpp)-mediated inhibition of the bacteriophage $\lambda p_{\mathrm{R}}$ promoter activity in Escherichia coli. Mol Gen Genet 257, 490-495.

Wróbel, B., Śrutkowska, S. \& Węgrzyn, G. (1998b). A lambdoid phage isolated from cultures of the commonly used Escherichia coli K12 stringent/relaxed strains CP78/CP79 after spontaneous prophage induction. Acta Biochim Pol 45, 251-259.

Yochem, J., Uchida, H., Sunshine, M., Saito, H., Georgopoulos, C. P. \& Feiss, M. (1978). Genetic analysis of two genes, dnaJ and dnaK, necessary for Escherichia coli and bacteriophage $\lambda$ DNA replication. Mol Gen Genet 164, 9-14.

Edited by: L. Jannière 